\section{"Women are the pillars of Our Culture": Bohna as a resurgent cloth among the Dhimal $^{1}$}

\section{Janak Rai}

\section{Abstract}

Bohna is the traditional ethnic dress woven and worn by Dhimal women. It is an everyday dress which Dhimal women wear it in all kinds of social spaces and events: home, fields, markets, cinema halls, colleges, mela, and other places. In the recent decades, with the resurgence of indigenous political movements and Dhimals' localized social movements for revival of their customary practices, bohna has emerged as a powerful marker of Dhimal indigenous identity. This paper examines the historical, cultural and political embeddedness of bohna in Dhimal society. The paper highlights the creative agency of Dhimal women by showing how weaving and exchange of bohna recreate and connect the embedded relations of affection, exchange and mutual obligations between Dhimal women.

Keywords: Cloth, Bohna, Dhimal, activism, ethnic identity

\footnotetext{
${ }^{1}$ I like to thank my friend Sarah Shepherd at University of Chicago, Illinois, for sharing her ideas and data on Dhimal weaving. This paper has greatly benefitted by her sharing.
}

\section{Introduction: Cloth as a marker of ethnic identity}

On the very hot afternoon of April 14, 2009, my scooter bike stopped working on way back from Raja Rani, a village located on a small hilltop nearby Letang bazar, Morang. I had gone there to observe and participate in the two day long inaugural of Shrejat Puja, the most important collective village ritual of Dhimal, one indigenous group from Nepal's easternmost lowlands in Morang and Jhapa districts. Each year, on the Nepali New Year, Dhimal Jati Bikas Kendra (hereafter the Kendra), the national level indigenous organization, organizes this particular ritual in the Raja Rani village. Thousands of Dhimal men, women and children from different villages attend this event and make ritual offerings to their deities in the Gramthan, Dhimal's shrine built in late 1990s. On this auspicious event, Dhimal women in particular come dressed in their traditional ethnic dress they call bohna or petani in Nepali.

After my scooter refused to operate, I had dragged it exhaustively for one hour, under the sun's heat along the sandy bank of Chisang River, in order to get to a small motorcycle repair store nearby the bus park in Letang bazar. I handed the bike to the mechanic who was a young boy in his early twenty, hoping that he would be able to fix it and rescue me from the possibility of being stranded in Letang that day. The mechanic, while checking the bike's oil filter, saw a group of Dhimal women wearing bohna passing from the other side of the road. "Where are all these Madhesi women coming from?" he asked. "No, no! They are not Madhesi; they are Dhimal. They have puja up there in Raja Rani. They are returning from there," the owner of the workshop, a local resident of Letang Bazaar, corrected his employee who had recently moved there from the city of Dharan, located about forty kilometers west-north of Letang.

This particular conversation that I overheard, by way of a serendipity, showed me how Dhimal bohna communicates to others not only who they are but also who they are not. The owner of the repair shop identified these Dhimali women by the cloth they were 
wearing and emphasized that they were not Madhesi. Dhimal strongly reject the identity of 'Madhesi' for them. They assert their claim of being the aboriginal people of their ancestral lands by saying, "We are not Madhesi. We are also not Pahade (people of hill origin)." In this particular event, Dhimal emphasis on 'not being Madhesi' was well carried by and conveyed through women's gendered and embodied practice of wearing Dhimal traditional ethnic dress for the ritual. With their dress, they successfully communicated an important political language of Dhimal indigeneity i.e. they are the indigenous/aboriginal inhabitants of Nepal easternmost Tarai, and they are distinct from the Madhesi as well as the Pahade people.

The preceding ethnographic vignette highlights how Dhimal traditional dress becomes a distinct marker of their ethnic identity, and underlines the social and political significance of cloth. The general purpose of this paper is to contribute to the general ethnography on the relations between cloth, gender relations, indigeneity, and politics in Nepal. More specifically, I discuss the importance of bohna in Dhimal society, and show how Dhimal women use bohna to reproduce their kin and social relationships (Schneider and Weiner, 1989) and connect themselves with their deities. By locating the continuity of bohna through weaving and wearing in the contexts of the state-led body politics of 'national dress' and the assimilative policies in the past, this paper also shows how cloth is embedded in the fields of power (see Allman, 2004). This historically informed analysis helps us to understand the collective agency of Dhimal women in resisting the assimilative state through their bodily praxis. I argue and show how bohna is a resurgent cloth Dhimal women create through their skill, labor and knowledge. Hence the bohna is more than marker of Dhimal ethnic identity. The paper builds on the 18 months long ethnographic research that I undertook between 2007 and 2009 in Dhimal village of Morang.

\section{Bohna - the power of an everyday dress}

Bohna, also called Petani in Nepali, is a single piece of long (about 3 meters) cotton cloth woven in black color as the background with red, orange/yellow or purple stripes in the middle. ${ }^{2}$ A traditional garment that Dhimal women weave and wear in their everyday life, the bohna has become one of the most powerful emblems of 'Dhimal identity' in the post-1990 period of resurgent indigenous politics in Nepal. Women wrap bohna from their chest to below their knees. The most common bohna is the Da Bohna (Dabha means black in Dhimali), black with red colored stripes. The Da Bohna is "often associated with young girls, and with beauty, and it is the only bohna that brides wear at their own weddings. Overwhelmingly, it is also the first choice for attending weddings, visiting the market, or attending mela (festivals or fairs)" (Shepherd 2010, p. 16). It is the most widely used bohna, hence has become the iconic symbol of Dhimal jāti identity in indigenous activism and Dhimal public events like rituals, fairs, and meetings.

The bohna is everyday dress, not a special cloth to be used only on certain occasions and events. It is still primarily woven for personal and social uses, not for selling in the market. Dhimal women wear it in all kinds of social spaces and events: home, fields, markets, cinema halls, colleges, mela, and other places. The bohna in its design and style is distinct from that of the Pahade dress, the traditional dress of the dominant groups in particular, and its alterity: the dress of the Madhesi people. This everydayness and distinctiveness of bohna --the product of Dhimal women's knowledge, labor, skill and time, and their daily bodily adornment -- imbues this ubiquitous cloth with significant meaning as an ethnic marker in addition to its political meanings for Dhimal, for example in their indigenous activism (see Rai 2013).

In recent years, the bohna has also moved well beyond its

\footnotetext{
${ }^{2}$ There are different types of bohna. For the purpose of this study, I will simply call
} all these patterns bohna. On different types of bohna, see Shepherd (2006). 
undeniable importance in Dhimal contemporary indigenous activism. From the Dhimal beauty pageant competitions to their everyday college life, young Dhimal girls are creatively refashioning bohna in order to reclaim their ethnic identity and express their sense of being "suitably modern" (Liechty 2003). The public circulation of images of bohna-wearing Dhimal women representing 'Dhimal jāti' has intensified, thanks to the efforts of Dhimal themselves. Now Nepal's mainstream media (newspapers and TV), even when they do not cover the political agendas raised by Dhimal, seem 'inclusive' enough to circulate images of bohna wearing Dhimal women for public consumption.

The wider circulation of such images of bohna as the material emblem of Dhimal identity also signals the increasing public sensitivity to the multicultural realities of Nepali society. Even at the level of recognition of difference, the celebratory consumption of bohna in Nepal's “mediascape" (Appadurai, 1990) indicates the impact of Dhimal political mobilization, and that of the pan-national indigenous movements in Nepal after 1990. Now Dhimal-organized public cultural events and political mobilizations have become inconceivable without the concrete embodiment of Dhimal collective identity in the form of bohna adorned women. The increasing presence of bohna-wearing women in Dhimal indigenous activism reflects not only their 'participation' in the movement. It also underlines women's assertion of indigenous identity and their collective political agency to challenge their subordinated position in the nation, as well as within their own community and their indigenous political organizations.

"Dhimal women are the pillars of our culture," many Dhimal men proudly told me. Scholars have warned us to take cautiously such feminization of indigenous identity in indigenous political movements for its "naturalizing women identities with stereotypical female identification....and while (it) marginalizes their voices by providing very few spaces for actual political participation” (Muratoria 1998, p. 411). I acknowledge this important concern. Many women indigenous activists expressed similar views during various interaction programs I attended in Kathmandu during my fieldwork. However, all the Dhimal women leaders who I discussed the issues of the Dhimal ethnic dress and indigenous activism asserted their sense of pride of wearing their bohna on everyday basis as well as in their activism.

The anthropologist Ann-Elise Lewallen's (2006) work on the Ainu women of Japan has demonstrated, the increasing significance of cultural artifacts and knowledge associated with indigenous women in the indigenous political movement can also empower indigenous women as political actors. During the period of my ethnographic fieldwork (2007-2009), I encountered many instances whereby Dhimal women challenged the male leaders of the Kendra by saying that without bohna wearing Dhimal women, people will not definitely distinguish between Dhimal and non-Dhimal. They also ridiculed Dhimal men for giving up their traditional dress. Hence, Dhimal men's appreciative acknowledgement also helps us to understand Dhimal women as agentive culture maker on their own (Warren 1998).

With regard to the resurgence of the bohna, I argue that the cloth needs to be understood as more than the defining materiality of Dhimal identity by centering on women's skill, labor, and the kinship relations within which bohna continued to operate as an "inalienable possession" (Weiner 1992) of Dhimal women's social world. In order to understand bohna as the resurgent cloth, we need to locate women's collective agency in continuing to weave and wear bohna under the assimilative state policies as well as in the cultural embeddedness of bohna and its production.

\section{Bohna as a resurgent cloth}

Scholars have shown how dress practices become entrenched in the fields of power, economic, political, gendered, or generational (see Allman 2004; Lewallen 2006). The relationship between cloth and the fields of power becomes evident in the case of the disappearance of the traditional dress of Dhimal men. Dhari (Dh.) -- the traditional 
dress of Dhimal men -- is similar to Dhoti (in Nepali and Hindi), a common cloth that men wear in Nepal's Tarai and in India. ${ }^{3}$ Dhimal men's dress was still worn into the late 1960s, but it disappeared from everyday use by the late 1970 (Diwas 1980) after the arrival of the hill groups and the state-led assimilative policies of 'Nepalization' (Gaige 1975).

With the advent of the Panchayat regime in 1962 led by the King Mahendra, the ruling regime effectively used the notion of 'national dress' to foster a shared sense of 'Nepali identity' whereby all social groups were asked to consider 'Nepali language and dress dearer than their lives.' The irony in this national sentiment was that the 'language' and 'dress' was that of the dominant hill Hindu groups, which others were required to hold as dearer than their lives. Thus the Panchayat politics of national dress also illustrates "how relations of power are constituted, articulated, and contested through dress" (Allman 2004, p. 1). A major yet unspoken aim of these state policies of creating hill-centric 'Nepali' subjects was to assimilate the people of Tarai origin into the hill culture and to prevent the political influence of India in Nepal via the Tarai region (Gaige 1975).

Furthermore, when the traditional dress of the hill Hindu groups was recognized and promoted as the 'official dress,' Dhimal were required to mediate state-led body politics by distancing themselves from any visible markers that could designate them as "people of Indian origin." By the 1970s, Dhimal men, because of their increased participation in the public sphere, education, and interactions with state power, had become 'Nepalized' in their dress practice (Diwas 1980; Dahal 1979; Regmi 1985).

Dhimal women's experiences of state-led body politics were not different from those of Dhimal men. In the past Dhimal women had not worn blouses (Nep. Chola) with bohna i.e. the upper parts of their bodies above their chest were left uncovered, perhaps because of

${ }^{3}$ It is a rectangular piece of long unstitched cloth wrapped around the waist and the legs and knotted at the waist. The hill people often derogatively call the people of Tarai origin as 'Dhoti' to mark them as "Indians" from their idea that all Indians wear Dhoti. the heat of the Tarai climate. Dhimal women began wearing the blouse, I am told, when they encountered new neighbors moving in from outside the Tarai, with different worldviews about clothing and bodies. These incomers took the failure to wear a blouse as a form of "nudity" and questioned Dhimal women's morality and character (Regmi 1982; see Guneratne 2001 for similar experience of Tharus). Dhimal women began to wear blouses more frequently after the 1970s in public places like the markets, mela, and weddings (see Diwas 1982, pp. 41-53). The use of blouses, an innovative adoption by Dhimali women, added to the wider acceptance of the bohna in the larger society. Dhimal women continued to weave and wear bohna, but outside their domestic spaces it was displaced by the saree, kurta suruwal, and other 'modern' dresses. Still the continuity of the weaving and the wearing of bohna, though not in the same form, signify the social agency of Dhimal women to creatively withstand the very forceful assimilative conditions which had emerged after the 1950s in the Tarai.

\section{Bohna and Dhimal Sociality}

Why did Dhimal women continue to weave and use bohna? Were they not "modern" enough to wear other dresses (cf. Deloria 2004)? Where they so "poor" unable to afford "modern" clothes? I argue that the embeddedness of bohna in Dhimal social relationships, particularly among women, and its ritual roles largely contributed to its continuity. ${ }^{4}$ As with the Tamang women described by Kathryn March (1983), weaving represents dense symbols of gender, and the practices of weaving connect women in the "reciprocal network of affections and mutual obligation” (March 1983, p. 731), particularly with other women.

Weaving is a distinctive feminine skill that Dhimal women learn from their grand/mothers and other female kin groups at home in ${ }^{4}$ Weaving provided occasional cash income. But the bohna even at that time
of this writing is not produced for the market. 
their natal village. In the past, weaving was associated with women's character and hard work, and as such it constituted an important social embodiment related to social recognition, honor and prestige for women, their family and the village. For a young girl, her weaving skill was also associated with social preference for her marriageability. The skill and labor of weaving women produced many household garments such as blankets, rugs, bed sheets, and hammocks for babies, sacks and others. For Dhimal, then, women's weaving was an integral part of the household economy and sustenance.

Weaving also connected women with their ancestral deity, and so evokes their relationship with the spiritual power. Dhimal believe that weaving bohna is a divine skill that their ancestral grandmother, revered and worshipped under many names, among them Laxmi Berang, Dhobini Berang, and Sadi Berang, taught other women. Each year during the ritual celebration at a place called Raja Rani, the ancestral grandmother used to leave bohna and jewelry in a particular place so that the Dhimal women who were attending could use them during the ritual. At the end of the ritual, the women were expected to return these bohna and jewelry. At one such mela, some people, who had become greedy, did not return these items to the Grandmother, but instead took them home. The Grandmother got very angry at their greed and breach of trust. And she punished the entire village with death. Thus bohna carry deeper meanings related with Dhimal history, notions of morality, the power of Berang, and the senior women.

Parwa is one of the important three day long household ritual which falls during September-October during which Dhimal offer ritual worships to their deceased parents and other family members, and to all beings and things-such as rivers, water taps, cattle, household utensils, weapons, etc., which help them to subsist and survive throughout the year (Dhimal, S., 2011). Each year, during the Parwa ritual, Dhimal women unpack their weaving looms, wash all the parts with clean water, and worship them. In this ritual, the loom that works with Dhimal women for many months a year to produce cloths of their designs is revered as a deity, and its contribution is acknowledged and reciprocated with ritual offerings. "We have to thank this loom and ask it to be more enduring for the coming year. So we have to worship it today," bhauji (elder brother's wife) from my host Dhimal family explained to me during the Parwa ritual of 2009. The care, affection and respect that Dhimal women accord to their looms say much about their indigenous moral economy that produces the piece of cloth, now one of the most visible markers of Dhimal ethnic identity.

For Dhimal women, bohna gain special meanings during weddings. The bohna is an important wedding item that women must weave in other to gift it for the new bride coming to their villages or to their female kin or friends on their marriage. Similarly, the mother-inlaw must weave a new bohna and give it to her new daughter-in-law in the hope that before long, the new daughter-in-law will provide both a grandson and a granddaughter (Shepherd 2010). Even now, Dhimal women continue to make bohna in their free time for the wedding seasons. "Only lazy women will buy a readymade cloth (lungi, cotton cloth that women wear by wrapping around their waist) and give it as a wedding gift concealed in a paper wrapper," one Dhimal bohna weaver said as she explained to me in 2009 why they must weave the wedding gift. Thus the bohna, also a symbol of divine creation that is crafted through women's labor, skill and their sociality with other women, helps to recreate and connect the embedded relations of affection, exchange and mutual obligations between Dhimal women.

With the increasing Hinduization and 'modernization' of their local social worlds, Dhimal had given up the use of their ethnic dress as wedding dress by the early 1980s. The saree for the bride and shirtpants for the groom became the most widely used wedding dress. After 1990, following the political transformations towards recognition of ethnic identity and cultural diversities, and the resurgence of pan-national indigenous political movements for the recognition of indigenous identity and rights, revival of 'indigenous culture and traditions' proliferated across all ādivāsi communities. With the establishment of Dhimal Jati Bikas Kendra in the early 
1990s, Dhimal community leaders and activists led a strong localized social movement for enforcing Dhimal traditional clothes as 'wedding dress'. Now the uses of Dhimal traditional dress, bohna for the bride, and turban, kurta/shirt and suruwal for the groom have become mandatory for Dhimal wedding. In the early years, there were resistances by the youths to wear their everyday clothes as the special costumes for their wedding. However, now the use of Dhimal traditional dresses in the wedding have become mandatory, and it has become a widely practiced norm.

All the Dhimal whom I interviewed about this issue confirmed that nowadays the use of their ethnic dress as wedding dress is on the rise. Dhimal Jati Kendra and its cultural activists cited the revival of the use of their traditional dress in the wedding as an important achievement of their reform efforts. But the revival of and peoples' self-identification with one's 'ethnic dress' is also shaped by the larger political transformations in Nepal after the 1990s. The involvement and emergence of Dhimal youths as 'indigenous activists' in the recent years have enhanced the popularity of bohna both as a symbol of ethnic identity and a fashion object. Dhimal youth, women in particular, are creatively refashioning bohna and wear it with pride.

\section{Conclusion}

The larger political transformations after 1990 as well as Dhimals' collective and conscious efforts to reproduce their collectives through clothes have led to the resurgence of the popularity and the use of traditional ethnic dress among Dhimal.

Bohna has undoubtedly emerged as a powerful symbol of Dhimal ethnic identity, used as a political language through bodily praxis. In my analysis, I have attempted to move beyond the bohna as marker of Dhimal ethnic identity. Bohna is a symbol of divine creation that is crafted through women's labor, skill and their sociality with other women. The social and ritual use of bohna helps to recreate and connect the embedded relations of affection, exchange and mutual obligations in Dhimal community. As I have illustrated in this paper, we need to appreciate the historical and cultural embeddedness of bohna, and thereby acknowledge the creative agency of Dhimal women in order to understand how an everyday cloth can both engender and challenge power.

\section{References}

Allman, Jean Marie. (20004). Fashioning Africa: power and the politics of dress. In Jean M. Allen (ed). Fashioning Africa: power and the politics of dress, p. 1-12. Bloomington: Indiana University Press.

Appadurai, Arjun. (1996). Modernity at large: cultural dimensions of globalization. Minneapolis, Minn.: University of Minnesota Press

Dahal, Dilli (2036 V.S. (1979 A.D.). Dhimal Lok Jiwan Adhayan (Folk Life Study of Dhimal). Kathmandu, Nepal: Royal Nepal Academy.

Deloria, Philip Joseph. (2004). Indians in unexpected places.Lawrence, Kan.: University Press of Kansas.

Dhimal, Som. 2068 [2011]. Dhimāl Jātiko Cinārī [Introduction to Dhimal]. Lalitapur, Moràng Nepal: National Foundation for Development of Indigenous Nationalities (Nepal), Dhimā1 Jāti Bikā sa Kendra (Nepal). 
Diwas, Tulsi. (2035 (V.S.) 1978 A.D.). Pradarsanakari Dhimala loka-samskrti (Folk Cultures of Dhimal). Kathmandu: Nepal Rajkiya Pragya Pratisthan (Royal Nepal Academy).

Lewallen, Ann-Elise. (2006) Hands that Never Rest: Ainu Women, Cultural Revival, and Indigenous Politics in Japan. $\mathrm{PhD}$ Thesis, University of Michigan.

Liechty, Mark (2003). Suitably modern: making middle-class culture in a new consumer society. Princeton, N.J.: Princeton University Press.

Muratorio, Blanca. (1998). Indigenous Women's Identities and the Politics of Cultural Reproduction in the Ecuadorian Amazon. American Anthropologist 100(2):409.

Rai, Janak. (2013). Activism as a moral practice: history, placemaking and indigenous movements in Nepal. PhD Thesis, University of Michigan.

Regmi, Rishikeshab R. (1985). Cultural patterns and economic change: anthropological study of Dhimals of Nepal. Kathmandu, Nepal : Delhi: Sandeep Regmi ; Motilal Banarasi Dass.

Schneider, Jane and A. Weiner. (1989). Introduction. In Schneoder and Weiner, (Eds.) Cloth and Human Experience, p. 1-32. Washington: Smithsonian Institution Press.

Shepherd, Sarah. (2010). An Introduction to Dhimal Weaving. An Unpublished monograph.

Warren, Kay B. (1998). Indigenous movements and their critics: PanMaya activism in Guatemala. Princeton, NJ: PrincetonUniversity Press.
Weiner, Annette B. (1992). Inalienable possessions: The paradox of keeping-while-giving. Berkeley Univ of California Press. 